\title{
LA INCLUSIÓN DEL ERROR DE TIPO EN EL ORDENAMIENTO PENAL ECUATORIANO ${ }^{1}$
}

\author{
RAMIRO J. GARCÍA FALCONí ${ }^{2}$ \\ Káterin VALlejo VACA ${ }^{3}$ \\ UNIVERSIDAD CENTRAL DEL ECUADOR
}

\section{RESUMEN:}

El esquema del delito previsto en el Código Orgánico Integral Penal contempla al dolo como una modalidad de comisión del tipo, por lo que la sola ausencia del conocimiento total o parcial de los elementos objetivos darían paso a la aplicación del error de tipo, sin que su aplicación dependa del reconocimiento en la norma penal, sino de una consecuencia lógica como es el esquema conceptual contemplado en el COIP. Sin embargo, la ausencia de esta figura en nuestra legislación permitió la errónea interpretación de los jueces, respecto a su aplicación, por lo que la inclusión de ésta constituye un avance en la dogmática y en la futura jurisprudencia penal ecuatoriana.

1 Artículo recibido el 20 de enero de 2020 y aprobado el 20 de febrero de 2020.

2 Catedrático de Derecho penal y Derecho procesal penal de la Universidad Central del Ecuador. ORCID: 0000-0002-6343-563X

3 Catedrática de Derecho penal de la Universidad Central del Ecuador. ORCID: 0000-0002-7705-7318 


\section{PALABRAS CLAVE:}

Tipicidad, error de tipo, conocimiento, vencible, invencible, responsabilidad penal.

\section{ABSTRACT:}

The crime scheme provided for in the Comprehensive Organic Penal Code considers fraud as a modality of commission of the type, so the sole absence of total or partial knowledge of the objective elements would give way to the application of the type error; without its application, depends on recognition in Criminal Law, but on a logical consequence such as the conceptual scheme contemplated in the COIP. However, the absence of this figure in our legislation allowed the erroneous interpretation of the judges regarding its application, so its inclusion constitutes an advance in dogmatics and in future Ecuadorian criminal jurisprudence.

\section{KEY WORDS:}

Typicity, type error, knowledge, beatable, invincible, criminal liability.

Artículo 28.1.- Error de tipo. No existe infracción penal cuando, por error o ignorancia invencibles debidamente comprobados, se desconocen uno o varios de los elementos objetivos del tipo penal.

Si el error es vencible, la infracción persiste y responde por la modalidad culposa del tipo penal, si aquella existe. 
El error invencible, que recae sobre una circunstancia agravante o sobre un hecho que califique la infracción, impide la apreciación de ésta por parte las juezas y los jueces.

\section{El error en la legislación penal ecuatoriana}

Es evidente que la discusión penal en el país no ha sido muy afortunada y algo que debió delegarse a los expertos, lo asumieron al final del día los políticos. Esto explica varios de los errores de bulto con los que fue aprobado el Código Orgánico Integral Penal (COIP) en el 2014. La definición de dolo, la de delito omisivo con el preferir no actuar y sobre todo la exclusión del error, tanto de tipo, como de prohibición, fueron muestra del altísimo nivel de desconocimiento que marcó el debate. Si tenemos en cuenta que se suprimieron los errores de tipo y de prohibición a última hora, con argumentos como que se iba a propiciar la impunidad, o, peor aún, que estos instrumentos se iban a prestar a una mala utilización por parte de los operadores de justicia, dejamos evidenciada la ignorancia en el tema por parte de los actores legislativos y de gobierno, que al haber excluido dichos artículos, dejó a los operadores de justicia en un limbo que, ese sí, dio lugar a una aplicación arbitraria de estas figuras, pues unos jueces procedieron, de conformidad a las formas de error contempladas por la moderna dogmática penal y otros, la desconocieron, lo que significa que la responsabilidad o inocencia de una persona dependía de factores como la suerte y el ánimo del juez que conocía la causa.

Si el dolo contiene, tanto un elemento cognitivo (conocimiento), como uno volitivo (voluntad), resulta lógico preguntarse sobre cuál debe ser la respuesta del sistema penal, en el caso de la 
persona que actúa sin ese conocimiento. De igual forma, si el artículo 34 del COIP exige como elemento de la culpabilidad el conocimiento de la antijuridicidad del actuar, es menester analizar qué pasa cuando dicho conocimiento falta o es defectuoso. La existencia del error, sea de tipo o de prohibición, no depende, por tanto, de su reconocimiento en la norma penal, sino que se constituye en una consecuencia forzosa del esquema conceptual, manejado por el COIP. Esto ya sucedió en Alemania cuando en 1952, el Tribunal Supremo Federal dictó una sentencia, que reconoce estas formas de error, sin que estos se hayan encontrado expresamente señalados en el Código Penal.

\section{¿Podía negarse la existencia y aplicación del error de tipo y el error de prohibición, con base en el principio de legalidad y con el argumento de que estos fueron excluidos del COIP?}

Noy deningunamanera,como lovamos a demostrar, a continuación; el invocar el principio de legalidad para negar la aplicación de los errores de tipo y prohibición simplemente demostró un absoluto desconocimiento del contenido, perfil y límites del mencionado principio, por parte del juez que así procedía.

El principio de legalidad ya es formulado de forma elemental en la obra de BECCARIA ${ }^{4}$ al referirse a la decisión judicial como un

4 BECCARIA, CÉSAR señala que: Solo las leyes pueden decretar las penas de los delitos y esta autoridad debe residir únicamente en el legislador, que representa a toda la sociedad unida por el contrato social [...]. En todo delito debe hacerse por el juez un silogismo perfecto. Póndrase como mayor la ley general: por menor la acción, conforme o no con la ley de que se inferirá por consecuencia la libertad o la pena. Cuando el juez por fuerza o voluntad quiere hacer más de un silogismo, se abre la puerta a la incertidumbre. BECCARIA, CÉSAR. De los Delitos y de las Penas. 
silogismo, en el que la premisa mayor se encuentra constituida por la norma, la premisa menor por la conducta analizada y la conclusión, esto es la sentencia condenatoria o absolutoria, que dependerá de si la conducta se adecúa o no a la norma, que la define como delito. Esta formulación inicial es posteriormente desarrollada por Feuerbach, en su Tratado de Derecho Penal alemán ${ }^{5}$, bajo la fórmula: nullum crimen, nulla poena sine lege praevia (no hay delito, ni pena, sin ley previa). Este principio de mera legalidad penal ha sido desarrollado a su vez por LUIGI FERRAJOLI, quien plantea el principio de estricta legalidad, esto es considerar que si la función del Derecho penal es prevenir los delitos, el único modo de perseguirla racionalmente es indicar preventiva y exactamente sus supuestos típicos, en sede de amenaza legal, dado que solo se pueden prevenir y disuadir las acciones previstas, no las imprevistas, por dañinas que sean ${ }^{6}$.

La legalidad se refiere a la exigencia de someter la actividad penal del Estado a una ley previa a los hechos que se quieren sancionar, lo que impide su retroactividad, con la excepción de que se trate de una ley penal más benigna ${ }^{7}$, por lo cual ninguna sentencia condenatoria se puede dictar, aplicando una pena que no esté fundamentada en una ley previa, es decir, una ley en la que el hecho imputado al autor, sea amenazado con pena, lo cual implica que el razonamiento judicial debe comenzar con la ley ${ }^{8}$.

Montevideo, BdeF, 2011, pp. 14-19.

5 Feuerbach, A. R. V. Tratado de Derecho penal común vigente en Alemania en 1847. Buenos Aires, Editorial Hammurabi, 1989, p. 184.

6 Ferrajoli, L. Derecho y Razón. Madrid, Trotta, 2004, p. 278.

7 YACOBUCCI, G. El sentido de los principios penales. Buenos Aires, Ábaco de Rodolfo Depalma, 2002, p. 261.

8 Bacigalupo, E. Derecho penal. Parte General. Lima, ARA Editores, 
Este es el sentido del principio de legalidad en materia penal y no debe confundirse con el principio de reserva de ley, que en materia administrativa prohíbe realizarse aquello que no se encuentra expresamente contemplado en la ley. Prueba de ello es que en materia penal, por derivación del principio de lex estricta, la prohibición de analogía solo rige cuando se trata de la llamada analogía in malam partem, aquella que resulta ser extensiva de la punibilidad. Por el contrario, la interpretación analógica in bonam partem estaría legitimada en la interpretación de la ley penal, en consecuencia de que el derecho fundamental a la legalidad, nunca puede resultar vulnerado, cuando se favorece al acusado?.

No cabe, por tanto, la objeción a la aplicación de un mecanismo, que elimine la responsabilidad penal o atenúe la misma, desde el principio de legalidad, supuesto en el que incurren, tanto el error de tipo, como el de prohibición.

\section{¿Por qué los errores de tipo y de prohibición son consecuencias necesarias de la estructura dogmática aplicada por el coIP?}

Conforme consta en los artículos 26 y 34 del CoIP, tanto para el dolo, como para la culpabilidad se exige una forma de conocimiento de los elementos del tipo objetivo, en el primer caso, y de la antijuridicidad del actuar, en el segundo. La pregunta obvia que debemos formularnos es: ¿qué pasa cuando ese conocimiento no existe o es deficiente?, pues de lo contrario caeríamos en el equívoco de considerar que aún sin existir el conocimiento requerido por la propia ley, éste debe darse por

2004, p. 100.

9 Ibíd. pp. 123-124. 
supuesto. Éste no es un tema nuevo y su discusión ya supera el siglo de existencia y comienza por la vieja división entre error de hecho y error de Derecho.

La vieja nomenclatura utilizada hasta el Código anterior al COIP se fundamentaba en la división del error en aquellos referidos al hecho (facti) y el que recaía sobre asuntos de Derecho (juris). Hasta la emisión del COIP, el primero eximía de culpabilidad y el segundo resultaba irrelevante, bajo el principio error juris nocet, que derivaba del Derecho canónico, que distinguía entre error juris naturalis y error juris civilis ${ }^{10}$. Esta división caduca fue mantenida también en lo doctrinal como, por ejemplo, en el Manual de ERnesto Albán, en el cual al error de hecho se lo divide en esencial y accidental, mientras que al error de Derecho, ubicado al igual que el primero en la culpabilidad, no se le atribuye efecto exculpativo alguno ${ }^{11}$. El Estatuto de Roma, que mantiene una estructura mixta, entre el esquema anglosajón y el continental, contempla todavía los errores de hecho y de Derecho, en su artículo 32.

Muchos autores caen en el error de considerar al finalismo como el generador de la diferencia, entre la vieja y la nueva nomenclatura, pero ésta es bastante anterior a la mal llamada teoría final de acción. De hecho, Alexander Graf Zu Dohna, en 1924, ya establece la falta del dolo, cuando el autor no ha conocido la existencia de circunstancias de hecho que pertenecen al tipo ${ }^{12}$,

10 Zaffaroni, E. R. Derecho Penal. Parte General. Buenos Aires, Ediar Editores, 2002, p. 531.

11 Albán Gómez, E. Manual de Derecho Penal ecuatoriano. 13. a ed. Quito, Ediciones Legales, 2011, pp. 214-215.

12 Graf Zu Dohna, A. La Ilicitud. La estructura de la teoría del delito. 
así como hace referencia al error de prohibición. El mérito del finalismo está, sin duda, en la ubicación sistémica del error de tipo y el error de prohibición, en sede de tipicidad, el primero, y de culpabilidad, el segundo, desde la perspectiva de la norma penal, fundamentalmente, como norma subjetiva de determinación. La implantación de la distinción error de tipo y error de prohibición se produce con la emisión de la sentencia del Pleno de la Sala de lo Penal del Tribunal Supremo Federal alemán, en 1952, con base a los trabajos de Welzel ${ }^{13}$ y Busch ${ }^{14}$.

Es importante recalcar, además, que no es simplemente un cambio de nomenclatura la que se produce, al pasar del error de hecho y error de Derecho al error de tipo y error de prohibición. Cuando hablamos de una clasificación y de la otra, nos referimos a conceptos totalmente diferentes. Esto lo recalca Welzel, cuando enfatiza en que hay errores de hecho, que son errores de tipo, como, por ejemplo, la ajenidad de la cosa sustraída y hay errores de hecho, que son errores de prohibición, como el error que recae sobre los presupuestos fácticos de una causal de justificación ${ }^{15}$. Ejemplo de este último caso es quien mira a una persona meter su mano en su abrigo y considerando que va a ser atacado, dispara al supuesto agresor, cuando éste simplemente iba a sacar su teléfono móvil para hacer una llamada. De igual

Buenos Aires, Librería El Foro, 2006, p. 167.

13 Welzel, H. Süddeutsche Juristen-Zeitung. Heidelberg, Schneider, 1948, p. 368.

14 Busch, R. "Über dir Abgrenzung von Tatbestands- und Verbotsirrtum", en Festschrift für Edmund Mezger zum 70. Geburtstag, München, Beck, 1954, p. 165.

15 Welzel, H. Derecho Penal alemán. Santiago de Chile, Editorial Jurídica de Chile, p. 197. 
forma un error de Derecho puede ser un error de tipo, como en el caso de la persona que comercializa una sustancia que considera lícita, cuando ésta se encuentra enlistada como estupefaciente o psicotrópica.

Todas estas consideraciones, fueron tomadas en cuenta en la reforma al COIP de diciembre de 2019, en la que, entre otros aspectos, se incluye expresamente los errores de tipo y prohibición en el texto del Código, con lo que se subsana un yerro y un vacío importante del original de 2014. Sin embargo, por la extensión que tomaría explicar dicha incorporación en el presente artículo, solo se abordará el error de tipo.

\section{Error de tipo}

Al referimos al tipo, históricamente debe mencionarse como antecedentes de éste al corpus delicti y a FARINACIUS (1581). El corpus delicti englobaba todos los supuestos acerca de las características externas de la consumación de un injusto penal, estudios que se realizaron durante el siglo XVIII e inicios del $\mathrm{XIX}^{16}$. La teoría del hecho (Tatbestand), desarrollada por ERnEST Beling, atribuyó al tipo una autonomía en la estructura del delito, lo que llevó a la configuración de una nueva categoría dogmática denominada tipicidad, precedente a las ya existentes, antijuridicidad y culpabilidad.

El COIP se decanta por un lineamiento finalista, de manera que la tipicidad se la debe entender desde una doble perspectiva, teniendo en cuenta, tanto el aspecto objetivo y subjetivo dentro de esta

16 Strantenwerth, G. Derecho Penal. Parte General I. Buenos Aires, Editorial Hammurabi, 2005, p. 125. 
categoría dogmática. En palabras de Welzel el tipo objetivo es el núcleo real-material de todo delito; la fundamentación de éste radica en la objetivación de la voluntad, reflejada en un hecho externo, el cual constituye la base de la estructuración dogmática del delito. Por su parte la objetivación de la voluntad encuentra su expresión en las circunstancias objetivas del hecho, las cuales pertenecen al tipo objetivo ${ }^{17}$. Con el aspecto objetivo, se mira la cara externa u objetiva de la descripción típica, el cual contiene elementos del mundo exterior, así como también otros elementos, que pueden abarcar una valoración más allá de lo estrictamente descriptivo, por ello, las características estructurales del tipo penal pueden ser de índole descriptiva o normativa ${ }^{18}$. La diferencia entre los aspectos internos y externos de la acción no significa que el tipo objetivo es totalmente autónomo, con respecto al tipo subjetivo; por el contrario, esta diferencia es meramente analítica, ya que solo con la conjugación, tanto del tipo objetivo, como del tipo subjetivo puede determinarse la existencia de una acción jurídico penal ${ }^{19}$. Es importante destacar la configuración del tipo objetivo, ya que el error de tipo, como se analizará más adelante, recae sobre la existencia de una de las circunstancias o elementos pertenecientes a éste.

Con el advenimiento del finalismo, se produce una reconfiguración en el concepto de acción, adicionalmente, una nueva concepción de la norma penal como norma subjetiva de

17 Welzel, H. Derecho Penal alemán. Santiago de Chile, Editorial Jurídica de Chile, 1993, p. 77.

18 Velásquez, F. Manual de Derecho. Penal Parte General. Medellín, Comlibros, 2007, p. 269.

19 Fernández Carrasquilla, J. Derecho Penal. Parte General. Teoría del delito y de la pena. Santa Fe de Bogotá, Ibáñez, 2011, p. 117. 
determinación y el abandono de la teoría del dolo para instaurar la teoría de la culpabilidad. Estas inclusiones determinaron que se reconceptualicen varios elementos de las categorías dogmáticas, sin embargo, el cambio sustancial se produce con el traslado del dolo y la culpa a sede de tipicidad, los cuales hasta entonces se los analizaba en la culpabilidad. El dolo pasa a la parte subjetiva de la tipicidad, con el conocimiento de los elementos del tipo objetivo como único componente del aspecto cognitivo. Se defiende un concepto de dolo en el cual éste no admite el conocimiento de la antijuridicidad de la conducta, sino únicamente un conocimiento de la realización del tipo objetivo. La tipicidad deja de considerarse una categoría estrictamente objetiva y se valora un aspecto objetivo y otro subjetivo dentro de ésta.

En la acción se dan los elementos exteriores objetivos, y los elementos subjetivos transcurren en la conciencia del autor, lo que la dogmática llama el tipo subjetivo ${ }^{20}$. El tipo de injusto requiere siempre una parte subjetiva, lo que desde la perspectiva de la antijuridicidad se lo conoce como el desvalor subjetivo de la acción, integrado por el dolo o por la culpa, en consecuencia, no sólo en los tipos con específicos elementos subjetivos del injusto se requerirá una parte subjetiva, sino en todos los tipos penales $^{21}$.

Por una parte, el concepto de dolo exige que se cumpla el requisito del conocimiento de los elementos objetivos del tipo. Toda

20 Bacigalupo, E. Lineamientos de la teoría del delito. Buenos Aires, Editorial Hammurabi, 2007, p. 80.

21 Luzon PeñA, D. M. Lecciones de Derecho Penal. Parte General. 2. ${ }^{a}$ ed. Valencia, Tirant lo Blanch, 2012, p. 232. 
acción consciente es conducida por la decisión de la acción, es decir, por la conciencia de lo que se quiere. Esta parte intelectual comprende el conocimiento actual de todas las circunstancias objetivas del hecho del tipo legal, pues no es suficiente que el autor conociera potencialmente las circunstancias del hecho, es decir que pudiera hacerlas aflorar en su conciencia, sino que ha debido tener realmente la conciencia de ellas en el instante de su hecho, habérselas representado, haberlas percibido, haber pensado en ellas, siendo eso sí diferente la intensidad de la conciencia, según si se trata del fin de los medios o de una circunstancia concomitante $^{22}$, esto es aquéllos que pertenecen al tipo básico, como los que conforman las circunstancias atenuantes y agravantes ${ }^{23}$. Es decir, para la doctrina finalista y mayoritaria, se comprende el dolo como parte de la fase subjetiva del tipo de injusto y es requisito para realizar el análisis de la antijuridicidad de la conducta. Como consecuencia, se sostiene que el dolo requiere exclusivamente de un conocimiento de los elementos objetivos del tipo, pero no conciencia de la antijuridicidad o prohibición, que es un requisito distinto al dolo, el cual pertenece a la culpabilidad ${ }^{24}$.

El error de tipo existe cuando el autor no conoce alguno de los elementos a los que el dolo debe extenderse, según el tipo objetivo que corresponda, este error puede fundamentarse, tanto en una representación falsa, como en la falta de representación, pues de modo general el error radica en la no coincidencia

\footnotetext{
22 Welzel, H. Derecho Penal alemán, op. cit., p. 78.

23 Bacigalupo, E. Justicia Penal y Derechos Fundamentales. Madrid, Marcial Pons, 2002, p. 533.

24 Luzon Peña, D. M. Lecciones de Derecho Penal. Parte General. 2. a ed. Valencia, Tirant lo Blanch, 2012, p. 237.
} 
entre la conciencia y la realidad ${ }^{25}$. El dolo es un elemento estructural, perteneciente al tipo subjetivo, el cual contiene el conocimiento de las circunstancias contenidas en el tipo objetivo, la ausencia de éste constituye la falta de un elemento estructural, lo que la doctrina denomina error de tipo, pues éste conlleva la falta del elemento cognitivo ${ }^{26}$. El error rompe las relaciones cognoscitivas, ya que las impresiones sensibles y las intuiciones de los sujetos no siempre representan la verdad, esto se debe a la influencia de los factores intermedios, entre el sujeto y el objeto, como son los defectos referentes a la percepción, las imágenes complementarias, los prejuicios y las interpolaciones del pensamiento del sujeto; todos estos factores intermedios, entre el sujeto y el objeto, son las fuentes del error, lo cual resulta innegable, ya que lo conscientemente dado no siempre es idóneo para tener un conocimiento adecuado de la realidad o de lo objetivo ${ }^{27}$. El conocimiento del autor debe referirse a los elementos del tipo, que residen, tanto en la pasado, como en el presente, debiendo, además, prever el autor que el resultado exigido por el tipo sucederá o podrá suceder, y reconocer en sus rasgos esenciales la forma en la que la acción origina dicho resultado ${ }^{28}$. Estrictamente, el elemento cognoscitivo en el dolo consiste en la conciencia de la realización de los elementos objetivos restantes, de la producción del resultado y, además, del curso casual, entre la acción y el resultado, por lo tanto, en un

25 JescheCK, H. H. Tratado de Derecho Penal. Parte General. 5. a ed. Olmedo Cardenete, M. (trad.). Granada, Comares, 2002, pp. 328-329.

26 Bustos Ramírez, J. Obras Completas. T. I. Derecho Penal. Parte General. Lima, ARA Editores, 2005, p. 852.

27 Kropp, G. Teoría del conocimiento. T. I. Ciudad de México, Editorial Hispano Americana, 1961, p. 83.

28 JesCheCK, H. H. Tratado de Derecho Penal. Parte General. op. cit., p. 314. 
sentido obligatorio el autor debe conocer la peligrosidad de la acción, desde un punto de vista ex ante ${ }^{29}$.

De lo dicho, el error de tipo tiene que ver con el desconocimiento del tipo penal y de sus circunstancias, por lo que se puede afirmar que quien no conoce esa circunstancia además del tipo penal actúa $\sin$ dolo $^{30}$.

El error de tipo recae exclusivamente sobre los elementos pertenecientes al tipo objetivo, pues en la medida que solo se da valor al error esencial, éste no puede recaer sino sobre los elementos constitutivos de la descripción típica ${ }^{31}$; es un desacierto limitar al error de tipo sólo a lo fáctico, es decir que no afecte a los elementos normativos del tipo, en este sentido caben algunas reflexiones referentes al concepto de neutralidad valorativa del tipo, la realidad del mundo social del obrar humano es una realidad de significaciones y no indiferente al sentido ${ }^{32}$. Los elementos normativos como se analizará más adelante, no tienen nada que ver con la antijuridicidad, y sin embargo, el tipo contiene no sólo elementos que se conocen por los sentidos sino otros que son psíquicamente comprendidos ${ }^{33}$.

\footnotetext{
29 Cerezo Mir, J. Obras Completas de Derecho Penal. Ara Editores, Lima, 2006, p. 519.

30 DonnA, E. Derecho Penal. Parte General. T. IV. Buenos Aires, Rubinzal Culzioni, 2007, p. 230.

31 Bacigalupo, E. Tipo y error. Buenos Aires, Editorial Hammurabi, 2002, p. 105.

32 Welzel, H. “Comentario al fallo del BGH, de 28/10/52”, en JZ, p. 120. 33 Ibíd.
} 
Resulta lógico que no exista dolo al no cumplirse con las exigencias de conocimiento de los elementos del tipo objetivo, pues este conocimiento es un elemento constitutivo del dolo; lo valioso de este análisis radica en que al autor pueda serle imputado como hecho doloso sólo aquella medida de lo ilícito que le era conocido, adicionalmente rige en los casos de desconocimiento de circunstancias que si bien no fundamentan el ilícito, si lo aumentan (elementos accidentales del tipo), y en caso de suposición errónea de circunstancias que lo disminuyen ${ }^{34}$. En caso de que el autor no conozca una de las circunstancias que integran el tipo, se habla de un error de tipo, esto rige independientemente de si el autor habría podido evitar su error o no, la evitabilidad de un error de tipo tiene importancia únicamente para la punición, ya que de darse el caso se podría incurrir en un tipo penal imprudente ${ }^{35}$.

Si el sujeto yerra sobre las características objetivas del tipo, no se podrá establecer una concurrencia entre el aspecto objetivo y subjetivo por la falta de este último, como consecuencia el tipo no se concreta y la conducta es atípica, se debe resaltar que la falta del aspecto subjetivo del tipo se ha planteado con énfasis frente al delito doloso, sin embargo no se deja de reconocer que las formas delictivas de los delitos culposos son semejantes a las de los delitos dolosos ya que el aspecto subjetivo del delito culposo también es final, aunque rezagado del tipo objetivo de los delitos dolosos en la medida que el sujeto no dirige su actividad hacia la configuración del tipo ${ }^{36}$, en esta clase de delitos

\footnotetext{
34 Stratenwerth, G. Derecho Penal. Parte General I. op. cit., pp. 179-180.

35 Frister, H. Derecho Penal. Parte General. Buenos Aires, Editorial Hammurabi, 2011, pp. 232-233.

36 Salazar Marín, M. Injusto penal y error. Santa Fe de Bogotá, Ediciones Jurídicas Gustavo Ibáñez, 2003, p. 159.
} 
como en los delitos dolosos, la tipicidad de una conducta se la realiza mediante un juicio de subsunción, por tanto la atipicidad dentro de los delitos imprudentes se da cuando falta un elemento estructural del tipo o por la falta del desvalor social típico en el hecho concreto ${ }^{37}$. En los delitos dolosos se ha analizado que puede existir directamente un error de tipo por el desconocimiento de uno de los elementos pertenecientes al tipo objetivo o a su vez una causa de atipicidad. Como consecuencia de lo afirmado, el error de tipo no afecta por tanto al conocimiento o desconocimiento de la antijuridicidad, sino tan solo a las circunstancias del hecho, lo cual puede devenir en el problema de delimitar el error de tipo del error de prohibición y la cuestión de que tan clara e intensa debe haber sido una representación en la consciencia de quien actúa para poder hablar de conocimiento en el sentido del Derecho penal ${ }^{38}$.

Es importante saber que el conocimiento de las circunstancias del hecho, el cual al faltar excluye el dolo, es diferente según el tipo de la circunstancia del hecho, pues el error opera de manera diferente si se trata de elementos descriptivos o elementos normativos del tipo ${ }^{39}$. Desde un presupuesto kantiano el error sobre los estados internos e intuitivos del sujeto parte sobre la ética trascendental, que así como mediante el sentido externo nos representamos objetos exteriores a nosotros, también en un

37 Bustos Ramírez, J. Obras Completas. T. I Derecho Penal. Parte General. op. cit., p. 852.

38 Roxin, C. Derecho Penal. Parte General. Luzón Peña, D. M., Díaz y García Conlledo, M., y De Vicente Remesal, J. (trad.), T. I., 2. ${ }^{a}$ ed. Madrid, Thomson-CIVITAS, 2010, p. 459.

39 Roxin, C. Problemas Actuales de la Dogmática Penal. Lima, ARA Editores, 2004, p. 121. 
sentido interno, por medio del cual el espíritu se contempla a sí mismo o sus estados interiores, no nos da en verdad alguna intuición sobre el alma misma como objeto, empero otorga una forma determinada bajo la que sólo mediante este análisis es posible la intuición de su estado interno ${ }^{40}$.

Para que el tipo cumpla con su función de garantía, debe redactarse de tal modo que de su texto se pueda deducir con claridad la conducta prohibida, para ello hay que utilizar un lenguaje claro y asequible al nivel cultural medio, se debe ser escueto en la utilización de elementos normativos, que implica un cierto grado de valoración subjetiva, y emplear elementos descriptivos que cualquiera pueda conocer sin mayor esfuerzo ${ }^{41}$. Sin embargo, en casos excepcionales es necesario recurrir a términos con un significado puramente técnico ya que las personas que están en condiciones de realizar la conducta típica suelen ser especialistas y conocen el lenguaje técnico utilizado en el tipo penal específico ${ }^{42}$. Si bien es cierto, los tipos penales aparentemente describen en forma exacta el hecho ilícito, estos están compuestos de desiguales elementos.

\section{Elementos descriptivos y normativos del tipo}

Es usual la distinción entre los elementos descriptivos y los elementos normativos, aunque resulta complejo realizar una distinción precisa. En el análisis de los elementos descriptivos

\footnotetext{
40 KAnT, E. Critica de la razón pura. del Perojo, J. (trad.), 4. ${ }^{\text {a }}$ ed. Santa Fe de Bogotá, Universales, 1983, p. 175.

41 Muñoz Conde, F. Derecho Penal. Parte General. Valencia, Tirant lo Blanch, 2004, p. 256.

42 Ibíd.
} 
puntualmente se los asocia con los hechos objetivos que son perceptibles desde un punto de vista sensorial. La tarea de los elementos descriptivos es detallar a un tipo penal de la manera más concluyente posible, excluyendo así la variable de valoración judicial $^{43}$, son aquellos elementos que a través de una percepción sensorial son conocidos por el autor, por tanto se los verifica mediante una constatación fáctica ${ }^{44}$. Los elementos descriptivos expresan una realidad naturalística, pero debe notarse que en ocasiones se necesita en cierto punto de una apreciación valorativa para precisar los elementos ${ }^{45}$, estos elementos que están contenidos en el tipo, son aquellos cuya percepción se la realiza a través de los sentidos ${ }^{46}$. En conclusión, el elemento descriptivo es percibido sensorialmente, esto es a través de los sentidos, especialmente la vista y el tacto. Así cuando hablamos de personas, cosas, fondos, bienes, etc. ${ }^{47}$.

Inicialmente, los autores llamaron la atención sobre la existencia de los elementos normativos en el tipo, la constatación de estos elementos es una de las principales críticas al causalismo naturalista ya que hasta entonces se consideraba a la tipicidad como una categoría dogmática que se limitaba a meras descripciones

43 Maurach, R., y Zipf, H. Derecho Penal. Parte General. T. I. Buenos Aires, Astrea, 2004, p. 365.

44 López Barja de Quiroga, J. Tratado de Derecho Penal. Parte General. Navarra, Aranzadi, 2010, p. 379.

45 Mir Puig, S. Derecho Penal. Parte General, 4. ${ }^{\text {a }}$ ed. MontevideoBarcelona, BdeF-Reppertor, 2005, p. 235.

46 Righi, E. Derecho Penal. Parte General. Buenos Aires, Lexis Nexis, 2007, p. 167.

47 Roxin, C. Problemas actuales de la Dogmática Penal. op. cit., p. 121. 
objetivas del hecho ${ }^{48}$. Es MAYER quien incluye los elementos normativos dentro de la tipicidad el cual señala que todo hecho tiene dos lados, así como todo tipo penal tiene dos partes: de las propiedades que lo caracterizan, existen algunas que acontecen en el mundo exterior y son perceptibles por los sentidos humanos $\mathrm{y}$, las características que se cumplen en el interior del sujeto; por tanto se distingue entre el hecho que consiste exteriormente, de lo que sucede en el plano psíquico del sujeto ${ }^{49}$. Sin duda la complejidad de los elementos normativos en un principio afecta la función de garantía del tipo ya que esta clase de elementos están sujetos a un previo juicio valorativo en el cual se corre el riesgo de la indeterminación y la subjetivización ${ }^{50}$.

Estos elementos son parte integrante de un resultado típico que tienen un significado valorativo, como partes integrantes de la acción, estos se diferencian de las relaciones de la acción y son, por lo demás reconocibles con mayor facilidad por una propiedad que les falta: son partes integrantes del resultado que no están en relación causal con la actuación voluntaria ${ }^{51}$. Por otra parte, los elementos normativos existen solamente en el ámbito de las representaciones valorativas, por lo que solo puede ser comprendido espiritualmente ${ }^{52}$, estos elementos no pueden ser

48 Bustos Ramírez, J. Obras Completas. T. I, Derecho Penal. Parte General. op. cit., p. 805.

49 MaYer, M. E. Derecho Penal. Parte General. Buenos Aires, B de F, 2007, p. 9.

50 Bustos Ramírez, J. Obras Completas. T. I, Derecho Penal. Parte General. op. cit., p. 805.

51 MaYer, M. E. Derecho Penal. Parte General. Buenos Aires, B de F, 2007, p. 228.

52 Roxin, C. Problemas actuales de la Dogmática Penal. op. cit., p. 121. 
conocidos a través de los sentidos, por lo que es necesario una valoración subjetiva ya que no se trata de hechos, sino que para conocerlos es obligatorio realizar un juicio de valor ${ }^{53}$.

Para la teoría del error esto significa que en los elementos descriptivos se presenta un error de tipo excluyente del dolo cuando falte o sea errónea la percepción sensorial, mientras que el error de tipo respecto de los elementos normativos se produce cuando al autor le falta el entendimiento espiritual necesario para comprenderlo ${ }^{54}$.

\section{Clases de error de tipo}

Fundamentalmente se clasifica al error de tipo en aquellos que se refieren a elementos esenciales del tipo y los que versan sobre elementos accidentales, clasificación que se encuentra implícita en la redacción del artículo comentado. Los primeros se subdividen en vencibles o invencibles, utilizándose por algunos autores la nomenclatura de evitables e inevitables ${ }^{55}$. Son elementos esenciales del tipo aquellos que pertenecen a la parte fundamental de este, como la conducta, los elementos normativos, los valorativos o los descriptivos. Se ha dicho que el error de tipo puede recaer sobre los elementos del supuesto de hecho constitutivo del delito, no obstante desde el punto de vista del error de tipo lo que importa realmente es establecer si se trata de elementos que fundamentan o modifican la pena ${ }^{56}$.

53 López Barja de Quiroga, J. Tratado de Derecho Penal. Parte General. op. cit., p. 379.

54 Roxin, C. Problemas actuales de la Dogmática Penal. op. cit., p. 122.

55 DonnA, E. Derecho Penal. Parte General, T. IV, op. cit. p. 254.

56 BaCigaluPo, E. Tipo y error. Buenos Aires, Editorial Hammurabi, 2002, p. 154. 
La vencibilidad se la determinará basándose en el concreto ámbito de actuación del autor, esto se establece en atención a sus circunstancias personales, pudiendo imputársele el deber de haber examinado los aspectos peligrosos de su concreta actuación, de ser posible esta imputación, se puede afirmar que el autor tuvo un nivel de conocimiento sobre los efectos lesivos de su conducta que pudo evitar con una actuación diligente, lo que fundamenta que de haber un error de tipo vencible la responsabilidad pueda recaer sobre un tipo imprudente ${ }^{57}$, si la legislación lo reconoce.

Cuando el error fuere vencible, si bien se elimina el dolo, se acudirá a la forma culposa del mismo, en caso de existir esta, pues el error podría haber sido evitado prestando la debida diligencia. El criterio al que se acudirá se refiere a si el error es objetivamente vencible o evitable, de acuerdo a las posibilidades del hombre medio ideal según la correspondiente posición jurídica, colocado en la situación del autor y con los conocimientos de este ${ }^{58}$.

Cuando el error recae sobre uno de estos elementos esenciales y es invencible, esto es, aun cuando el sujeto ha actuado con la mayor cautela y diligencia, y no ha podido obviar el conocimiento equivocado, entonces se excluirá tanto el dolo como la culpa y la acción será atípica. Una error será invencible cuando este es objetivamente inevitable aún para el hombre medio ideal colocado en la situación del autor y empleando toda la diligencia objetivamente debida $^{59}$.

57 García Cavero, P. Lecciones de Derecho Penal. Parte General,. Lima, Grijley, 2008, p. 429.

58 Luzón Peña, D. M. Curso de Derecho Penal. Parte General. T. I, op. cit., p. 446.

59 Ídem. Curso de Derecho Penal. Parte General. T. I. Madrid, Editorial 
Por otro lado, si el error recae sobre elementos accidentales, como en el caso de las agravantes o hechos que cualifiquen la infracción, se excluirán estos elementos del análisis del delito, siempre que el error fuere invencible. De acuerdo al CoIP en el caso del error de tipo sobre los elementos accidentales de este, solo opera en el caso del error invencible.

En virtud de lo anterior, se establece que el error puede recaer en elementos típicos diversos; sobre el objeto de la acción, en el golpe o el momento de consumación y sobre la relación de causalidad, sin que dicha circunstancia excluya sus efectos. Tanto en Ecuador, como en otras legislaciones comparadas, no existe codificación específica, y bajo estas circunstancias no se excluye el dolo, subsistiendo por ende la responsabilidad penal.

Error sobre el objeto de la acción.- Referente a la equivocación en torno al objeto hacia el cual dirige el comportamiento el sujeto activo, es decir, la actividad del sujeto se dirige a un objeto determinado pero previamente éste puede ser confundido por otro, en principio resulta irrelevante la equivocación, es decir da lo mismo que prive de la vida a B en lugar de C, excepto cuando se trate de un supuesto en el cual el sujeto tenga cierta relación con A y eso dé lugar a la concreción de un tipo distinto como podría ser el homicidio con relación al parentesco, así la persona que mata a su padre, sin conocer la relación de parentesco existente, (caso Edipo Rey) habrá actuado con dolo, pero la circunstancia

Universitas, 2004, p. 445. 
del parricidio (artículo 139.1 COIP) no deberá ser tomada en cuenta ${ }^{60}$. Se produce un error sobre el objeto de la acción, al haberse producido un yerro en la identidad de la persona, y aun cuando su acción recayó sobre un objeto diferente, los dos tenían la misma protección por parte del derecho penal, por lo que persiste la responsabilidad.

Aberratio ictus.- Existe cuando el sujeto dirige su actividad a un objeto determinado, pero yerra y alcanza otro objeto de similar valor jurídico, más que un error se trata en este caso de una desviación externa de la actividad del sujeto ${ }^{61}$. El ejemplo clásico refiere al autor que pretende privar de la vida a B, pero por su mala puntería alcanza a C. Según la doctrinaria minoritaria, siguiendo la teoría de la concreción, en este caso nos encontraríamos ante una tentativa de delito de homicidio doloso contra $\mathrm{B}$, en concurso con un homicidio culposo contra $\mathrm{C}$, mientras que según la teoría de la equivalencia se sancionaría al autor por el delito de homicidio consumado, pues existe equivalencia en el objeto de la acción ${ }^{62}$.

En los supuestos anteriores estamos frente a errores sobre un elemento accidental, en la que subsiste el dolo, pues se trata de

\footnotetext{
60 Villavicencio, F. Derecho Penal. Parte General. Lima, Griley, 2006, p. 362.

61 Silvestroni, M. Teoría Constitucional del Delito. Buenos Aires, Editores del Puerto, 2004, p. 226.

62 RoxIN, C. Problemas actuales de la Dogmática Penal. Lima, ARA Editores, 2004, p. 124.
} 
una situación irrelevante, de un error accidental, en la que el autor responde por su comportamiento delictivo.

Error sobre el curso causal.- El sujeto activo yerra sobre el curso causal que producirá el resultado deseado ${ }^{63}$. Por ejemplo, A apuñala a B para matarlo en la mitad de la calle, sin embargo, B sobrevive, aunque días después fallece en el hospital, a consecuencia de las lesiones recibidas. En atención al error en el objeto de la acción, esta modalidad de error es irrelevante frente a las consecuencias jurídico penales.

Error de tipo inverso.- También denominado error al revés, implica la actuación dolosa, pero con imposibilidad de que se llegue a producir el tipo objetivo, es decir, aunque hay desvalor de la acción se excluye el desvalor del resultado ${ }^{64}$. El sujeto tiene el dolo de cometer la conducta, sin embargo, esta es atípica. Estos casos de ausencia de tipo, conforman al igual que los de tentativa inidónea, un error de tipo inverso.

En el error de tipo hay tipicidad objetiva, sin dolo (la enfermera cree que inyecta vitaminas y por error da veneno, causando la muerte de B); sin embargo, en el error de tipo inverso, el cual proviene de la ausencia de tipo, el autor cree que está presente

\footnotetext{
63 Ontiveros, M. Derecho Penal. Parte General. Ciudad de México, Editorial Ubijus, 2018, p. 245.

64 Arango Durling, v. Las causas de inculpabilidad. Ciudad de Panamá, Ediciones Panamá Viejo, 1998 p. 365.
} 
una circunstancia del tipo objetivo, que en realidad no existe (inyecta veneno a un muerto creyéndolo con vida); $y$, finalmente, el error de tipo invertido, propio de la tentativa inidónea, recae sobre la idoneidad de los medios o el comportamiento (el autor quiere matar con azúcar, que ha tomado con error vencible por veneno). 


\section{REFERENCIAS BIBLIOGRÁFICAS}

ALBÁN GÓMEZ,Ernesto, Manual de Derecho Penal ecuatoriano. 13. a edición. Quito, Ediciones Legales, 2011.

ARANGO DURLING, Virginia, Las causas de inculpabilidad. Ciudad de Panamá, Ediciones Panamá Viejo, 1998.

BACIGAlupo, Enrique. Tipo y error. Buenos Aires, Editorial Hammurabi, 2002.

. Derecho penal. Parte General. Lima, ARA Editores, 2004.

- Justicia penal y Derechos fundamentales. Madrid, Marcial Pons, 2002.

. Lineamientos de la teoría del delito. Buenos Aires, Editorial Hammurabi, 2007.

BECCARIA, César. De los Delitos y de las Penas. Montevideo, B de F, 2011.

BUSCH, Richard. "Über dir Abgrenzung von Tatbestands- und Verbotsirrtum", en Festschrift für Edmund Mezger zum 70. Geburtstag, München, Beck, 1954.

Bustos RAMíREZ, Juan. Obras Completas, Tomo I, Derecho penal. Parte General. Lima, ARA Editores, 2005. 
CAVAllero, Ricardo. El Delito imposible la Tentativa Inidónea en el Derecho penal argentino. Buenos Aires, Editorial Universidad S.R.L, 1983.

CEREZO MIR, José. Obras Completas de Derecho penal. Parte General. Lima, ARA Editores, 2006.

DONNA, Edgardo, Derecho penal. Parte General. Tomo IV, Buenos Aires, Rubinzal Culzioni, 2007.

FERnÁndez CARRASQuilla, Juan. Derecho penal. Parte General. Teoría del delito y de la pena. Santa Fe de Bogotá, Ediciones Legales de Gustavo Ibáñez, 2011.

FERRAJOLI, Luigi. Derecho y Razón. Madrid, Trotta, 2004.

FEUERBACH, Anselm Ritter von. Tratado de Derecho penal común vigente en Alemania en 1847. Buenos Aires, Editorial Hammurabi, 1989.

FRISTER, Helmut, Derecho penal. Parte General. Buenos Aires, Editorial Hammurabi, 2011.

GARCÍA CAVERO, Percy, Lecciones de Derecho penal. Parte General. Lima, Grijley, 2008.

GRAF ZU DOHNA, Alexander, La ilicitud. La estructura de la teoría del delito. Buenos Aires, Librería El Foro, 2006.

JESCHECK, Hans Heinrich, Tratado de Derecho penal. Parte General. 5. a edición, Olmedo Cardenete, M. (trad.). Granada, Comares, 2002. 
KANT, Emmanuel, Critica de la razón pura.4. a edición, del Perojo, J. (trad.), Santa Fe de Bogotá, Universales, 1983.

KROPP, Gerhard, Teoría del conocimiento. Tomo I. Ciudad de México, Editorial Hispano Americana, 1961.

LÓPEZ BARJA DE QUIROGA, Jacobo. Tratado de Derecho penal. Parte General. Navarra, Aranzadi, 2010.

LUZÓN PEÑA, Diego-Manuel. Curso de Derecho penal. Parte General. Tomo I. Madrid, Editorial Universitas, 2004.

. Lecciones de Derecho penal. Parte General. 2. edición. Valencia, Tirant lo Blanch, 2012.

MAURACH, Reinhart, y ZIPF, Heinz, Derecho penal. Parte General. Tomo I. Buenos Aires, Astrea, 2004.

MAYER, Max Ernst. Derecho penal. Parte General. Buenos Aires, B de F, 2007.

MIR PUIG, Santiago. Derecho penal. Parte General. 4. ${ }^{a}$ edición. Montevideo-Barcelona, B de F-Reppertor, 2005.

MuÑOZ CONDE, Francisco. Derecho penal. Parte General. Valencia, Tirant lo Blanch, 2004.

OnTIVEROS, Miguel. Derecho penal. Parte General. Ciudad de México, Editorial Ubijus, 2018.

RIGHI, Esteban. Derecho penal. Parte General. Buenos Aires, Lexis Nexis, 2007. 
ROXIN, Claus. Problemas actuales de la Dogmática Penal. Lima, ARA Editores, 2004.

. Derecho penal. Parte General. Tomo I, 2. ${ }^{a}$ edición, Luzón-Peña, Diego Manuel, Díaz y García Conlledo, Miguel, y De Vicente Remesal, Javier (trad.). Madrid, Thomson-CIVITAS, 2010.

SALAZAR MARÍN, Mario. Injusto penal y error. Santa Fe de Bogotá, Ediciones Jurídicas Gustavo Ibáñez, 2003.

SILVESTRONI, Mariano.Teoría constitucional del Delito. Buenos Aires, Editores del Puerto, 2004.

STRANTENWERTH, Gunter. Derecho penal. Parte General. Tomo I. Buenos Aires, Hammurabi, 2005.

VelásqueZ, Fernando. Manual de Derecho penal. Parte General. Medellín, Comlibros, 2007.

VILLAVICENCIO, Felipe. Derecho penal. Parte General. Lima, Griley, 2006.

WELZEL, Hans. Süddeusche Juristen-Zeitubg, Heidelberg, Schneider, 1948.

.Abhandlungen zum Strafrecht und zur Rechstohilosophie, Berlin, Walter De Gruyter, 1975.

. Derecho penal alemán, Santiago de Chile, Editorial Jurídica de Chile, 1993. 
YACOBUCCI, Guillermo, El sentido de los Principios penales, Buenos Aires, Ábaco de Rodolfo Depalma, 2002.

ZAFFARONI, Eugenio Raúl. Derecho penal. Parte General. 2. edición. Buenos Aires, Ediar Editores, 2002. 